\title{
Occupational disability caused by dizziness and vertigo: a register-based prospective study
}

\author{
Anne Kari Skøien, Kjersti Wilhemsen and Sturla Gjesdal
}

\author{
ABSTRACT \\ Background \\ Despite the magnitude of dizziness/vertigo in primary \\ health care, prospective studies are scarce, and few \\ studies have focused on vocational consequences. \\ Using the International Classification of Primary Health \\ Care (ICPC), GPs have two alternative diagnoses, H82 \\ (vertiginous syndrome) and N17 (vertigo/dizziness), \\ when issuing sickness certificates to these patients. \\ Aim \\ To assess the incidence of dizziness/vertigo in long- \\ term sickness absence and to identify \\ sociodemographic and diagnostic predictors for \\ transition into disability pension. \\ Design of study \\ Register-based prospective study, 5-year follow-up.

\section{Setting} \\ All individuals in Norway eligible for sickness absence \\ in 1997 (registered employed or unemployed).

\section{Method} \\ The risk of disability pension was assessed with Cox \\ proportional hazards analysis, with medical and \\ sociodemographic information as independent \\ variables, stratified for sex.

\section{Results} \\ Six-hundred and ninety-four women and 326 men were \\ included. Dizziness/vertigo made up $0.9 \%$ of long-term \\ sickness absence among women and $0.7 \%$ among \\ men. Among both women and men, $41 \%$ was certified \\ with $\mathrm{H} 82$ and $59 \%$ with N17: $23 \%$ of women and $24 \%$ \\ of men obtained a disability pension. Age was the \\ strongest predictor for obtaining a disability pension. \\ Subjects with only basic education had an almost \\ doubled risk of obtaining a disability pension compared \\ to the highest educational group. Women with $\mathrm{H} 82$ had \\ significantly higher risk for obtaining a disability \\ pension than those with N17. The difference increased \\ after adjustment for sociodemographic variables. Sex \\ had no effect when all other variables were controlled \\ for.

\section{Conclusion} \\ Dizziness/vertigo is an infrequent cause of certified \\ sickness absence, but long-term sickness absentees \\ with dizziness/vertigo have a considerable risk of \\ obtaining a disability pension in the future. \\ Keywords \\ disability insurance; dizziness; health insurance; risk \\ factors; sick leave; vertigo.
}

\section{INTRODUCTION}

Dizziness/vertigo challenges clinicians and researchers due to its subjective nature. Traditionally dizziness is subclassified into vertigo, presyncope, disequilibrium, and 'other types of dizziness'. ' This classification was introduced 35 years ago and is still in use..$^{2,3}$ Vertigo indicates vestibular disorder: benign paroxysmal positional vertigo (BPPV), vestibular neuritis, or Ménière's disease, and has constituted $30 \%$ of cases in previous studies. ${ }^{3-7}$ It has been claimed that vertigo can easily be distinguished from other causes of dizziness. ${ }^{3,8}$

Dizziness/vertigo is a common symptom, increasing with age, ${ }^{7}$ and the frequency is higher in women than men. ${ }^{7,9-15}$ Lifetime prevalence was estimated to be $30 \%$ in a German survey, ${ }^{11}$ while a study from Scotland reported $21 \%$ vertigo, 29\% unsteadiness, and $13 \%$ other types of dizziness. ${ }^{10}$ In a sample of general practices in London, $24 \%$ reported patients with dizziness in the last month. ${ }^{16}$ The studies differ, with unequal populations, different case definitions, and different measures of prevalence.

Prospective studies indicate that nearly $30 \%$ of the patients have symptoms after 12-18 months; ${ }^{17,18}$ however, knowledge of the vocational consequences is scarce. In a UK survey, $23 \%$ reported symptoms of dizziness, but only $1.5 \%$ had taken days off work. ${ }^{7}$ Sickness absence is an important measure of ill-health and social functioning, ${ }^{19,20}$ and permanent withdrawal

AK Skøien, PT, MSc, assistant professor, Department of Physiotherapy, Bergen University College; K Wilhelmsen, PT, $\mathrm{MSc}$, assistant professor, Department of Physiotherapy, Bergen University College, Norway and Department of Public Health and Primary Health Care, University of Bergen; $S$ Gjesdal, senior research fellow, MD, MPH, PhD, Department of Public Health and Primary Health Care, University of Bergen, Bergen, Norway.

Address for correspondence

Anne Kari Skøien, Department of Physiotherapy, Bergen University College, Møllendalsveien 6, 5009 Bergen, Norway. E-mail: aks@hib.no

Submitted: 29 September 2007; Editor's response: 30 December 2007; final acceptance: 1 April 2008. (c)British Journal of General Practice 2008; 58: 619-623. DOI: 10.3399/bjgp08X330744 


\section{How this fits in}

Few prospective studies have assessed the long-term prognoses of subjects with dizziness/vertigo. This study adds that dizziness/vertigo is a relatively rare cause of certified sickness absence, but long-term sickness absentees with dizziness/vertigo have a considerable risk of obtaining a disability pension in the future. the scheme. Disability pension is granted in cases of permanent, at least $50 \%$, incapacity for work, when all relevant treatment and rehabilitation approaches have been applied.

\section{Setting and participants}

In 1997, 920139 women and 1019216 men in Norway were eligible for sickness absence benefits. All cases with at least 8 weeks' sickness absence were recorded by The National Insurance Services. Anonymous data were transferred to a research database established by The National Insurance Services and Statistics Norway. Information from patients aged below 63 years with a main diagnosis of dizziness/vertigo were included in the study.

\section{Explanatory variables}

The main diagnosis for each case based on the ICPC. The ICPC is organised in chapters corresponding to organ systems: $\mathrm{H}$ includes otological and $\mathrm{N}$ neurological conditions. With respect to dizziness/vertigo, two diagnoses are available: H82 (vertiginous syndrome), and N17 (vertigo/dizziness). Sociodemographic variables were age, sex, income before tax in 1996, and educational level (years).

\section{Follow-up and endpoint}

The sample was followed from the start of the sickness absence spell until 31 December 2002, with granting of disability pension as the endpoint.

All legal inhabitants aged $16-66$ years are covered by

Table 1. Descriptive statistics of study sample, and percentages obtaining disability pension during follow-up, according to diagnosis and sociodemographic variables. $n=326$ men and 692 women on long-term sick leave >8 weeks with a diagnosis of dizziness or vertigo.

\begin{tabular}{|c|c|c|c|c|c|c|c|c|c|c|}
\hline \multirow[b]{2}{*}{ Variables } & \multicolumn{5}{|c|}{ Women } & \multicolumn{5}{|c|}{ Men } \\
\hline & $n$ & $\%$ & $95 \% \mathrm{Cl}$ & DP, \% & $95 \% \mathrm{Cl}$ & $n$ & $\%$ & $95 \% \mathrm{Cl}$ & DP, \% & $95 \% \mathrm{Cl}$ \\
\hline \multicolumn{11}{|l|}{ Diagnosis } \\
\hline H82 & 282 & 41 & 37 to 44 & 29 & 24-34 & 134 & 41 & 36 to 46 & 23 & 16 to 30 \\
\hline N17 & 412 & 59 & 56 to 63 & 18 & $15-22$ & 192 & 59 & 54 to 64 & 24 & 18 to 30 \\
\hline All & 694 & 100 & & 23 & $18-27$ & 326 & 100 & & 24 & 20 to 27 \\
\hline \multicolumn{11}{|l|}{ Age, years } \\
\hline $16-29$ & 85 & 12 & 10 to 15 & 2 & $0-6$ & 36 & 11 & 8 to 14 & 3 & 0 to 8 \\
\hline 30-39 & 204 & 29 & 26 to 33 & 9 & $5-13$ & 79 & 24 & 20 to 29 & 9 & 3 to 15 \\
\hline $40-49$ & 212 & 31 & 27 to 34 & 22 & $17-28$ & 87 & 27 & 22 to 31 & 17 & 9 to 25 \\
\hline $50-62$ & 193 & 28 & 24 to 31 & 47 & $38-52$ & 124 & 38 & 33 to 43 & 44 & 33 to 52 \\
\hline \multicolumn{11}{|c|}{ Education, number of years } \\
\hline Basic, 7-9 & 82 & 12 & 9 to 14 & 46 & $36-57$ & 59 & 18 & 14 to 22 & 44 & 31 to 57 \\
\hline Lower middle, 10-12 & 333 & 48 & 44 to 52 & 25 & $21-30$ & 131 & 40 & 35 to 46 & 21 & 14 to 28 \\
\hline Higher middle, 13-14 & 163 & 23 & 20 to 27 & 12 & $7-17$ & 102 & 31 & 26 to 36 & 15 & 8 to 22 \\
\hline Academic, $\geq 15$ & 113 & 16 & 14 to 19 & 14 & $8-21$ & 32 & 10 & 7 to 13 & 19 & 5 to 32 \\
\hline \multicolumn{11}{|c|}{ Annual income 1996, NOK } \\
\hline 0-79 999 & 63 & 9 & 7 to 11 & 22 & 19-25 & 18 & 6 & 3 to 10 & 13 & 9 to 16 \\
\hline $80000-159999$ & 236 & 34 & 30 to 38 & 25 & $22-29$ & 37 & 11 & 8 to 13 & 27 & 23 to 32 \\
\hline 160 000-239999 & 311 & 45 & 41 to 49 & 18 & $15-21$ & 143 & 44 & 38 to 49 & 25 & 20 to 30 \\
\hline$\geq 240000$ & 84 & 12 & 10 to 15 & 26 & $23-30$ & 128 & 39 & 34 to 45 & 20 & 15 to 24 \\
\hline
\end{tabular}

$D P=$ disability pension. $N O K=$ Norwegian krones $(1 \mathrm{GBP}=9.7 \mathrm{NOK})$. 
Table 2. Results of Cox regression analysis in full sample and separately for sexes: risk of transition to disability pension according to diagnosis and sociodemographic variables: $n=326$ men and $n=692$ women on long-term sick-leave with a diagnosis of dizziness or vertigo.

\begin{tabular}{|c|c|c|c|c|c|c|c|c|c|}
\hline \multirow[b]{2}{*}{ Variables } & \multicolumn{3}{|c|}{ All } & \multicolumn{3}{|c|}{ Men } & \multicolumn{3}{|c|}{ Women } \\
\hline & HR & $95 \% \mathrm{Cl}$ & $P$-value & $\mathrm{HR}$ & $95 \% \mathrm{Cl}$ & $P$-value & HR & $95 \% \mathrm{Cl}$ & $P$-value \\
\hline \multicolumn{10}{|l|}{ Diagnosis } \\
\hline N17 & 1.0 & & & 1.0 & & & 1.0 & & \\
\hline H82 & 1.5 & 1.1 to 1.9 & 0.003 & 1.0 & 0.6 to 1.6 & 0.992 & 1.7 & 1.3 to 2.4 & $<0.001$ \\
\hline \multicolumn{10}{|l|}{ Age, years } \\
\hline $16-39$ & 1.0 & & & 1.0 & & & 1.0 & & \\
\hline $40-49$ & 2.7 & 1.7 to 4.2 & & 2.4 & 1.0 to 5.7 & & 2.7 & 1.6 to 4.7 & \\
\hline $50-62$ & 6.6 & 4.3 to 10.1 & $<0.001$ & 6.2 & 2.8 to 13.5 & $<0.001$ & 6.6 & 3.9 to 10.9 & $<0.001$ \\
\hline \multicolumn{10}{|c|}{ Education, number of years } \\
\hline Academic, $\geq 15$ & 1.0 & & & 1.0 & & & 1.0 & & \\
\hline Higher middle, 12-14 & 1.0 & 0.6 to 1.6 & & 0.9 & 0.4 to 2.1 & & 0.9 & 0.5 to 1.7 & \\
\hline Lower middle, 10-11 & 1.6 & 1.1 to 2.5 & & 1.3 & 0.5 to 3.1 & & 1.7 & 1.0 to 2.8 & \\
\hline Basic, 7-9 & 2.0 & 1.2 to 3.2 & 0.001 & 1.8 & 0.7 to 4.4 & 0.024 & 1.9 & 1.1 to 3.4 & 0.004 \\
\hline \multicolumn{10}{|c|}{ Annual income 1996, NOK } \\
\hline$\geq 240000$ & 1.0 & & & 1.0 & & & 1,0 & & \\
\hline $160000-239999$ & 1.0 & 0.7 to 1.5 & & 1.2 & 0.7 to 2.0 & & 1.0 & 0.6 to 1.7 & \\
\hline $80000-159999$ & 1.2 & 0.8 to 1.8 & & 0.8 & 0.3 to 2.1 & & 1.3 & 0.7 to 2.3 & \\
\hline $0-79999$ & 1.2 & 0.6 to 2.2 & 0.120 & 0.4 & 0.0 to 2.8 & 0.490 & 1.4 & 0.7 to 2.8 & 0.170 \\
\hline \multicolumn{10}{|l|}{ Sex } \\
\hline Men & 1.0 & & & & & & & & \\
\hline Women & 1.1 & 0.8 to 1.4 & 0.670 & & & & & & \\
\hline
\end{tabular}

$H R=$ hazard ratio. $D P=$ disability pension. $N O K=$ Norwegian Krones $(1 \mathrm{GBP}=9.7 \mathrm{NOK})$.

\section{Analysis}

Survival analysis was carried out with Cox proportional hazards analysis for the full sample, and stratified for sex, with disability pension as the dependent variable. Sociodemographic variables and diagnoses were entered as explanatory variables. The hazard ratio $(\mathrm{HR})$ for obtaining disability pension, with 95\% confidence intervals (Cl), was identified for each variable. The statistical software program SPSS (version 13.0) was used.

\section{RESULTS}

Among all spells of long-term sickness absence in 1997, cases with dizziness/vertigo made up $0.9 \%$ of women and $0.7 \%$ of men. The descriptive statistics of the study sample are shown in Table 1; 694 women and 326 men were included, corresponding to an annual incidence for women of 7.5/10 000 at risk (vocationally active) and for men of 3.2/10 000 at risk (vocationally active). Among both women and men, $41 \%$ were certified with $\mathrm{H} 82$, and $59 \%$ with N17.

\section{Transition to disability pension}

Disability pension was obtained by $23 \%$ of the women and $24 \%$ of the men. Among women with an $\mathrm{H} 82$ diagnosis, $29 \%$ (95\% Cl = 24 to 34) obtained disability pension versus $18 \%(95 \% \mathrm{Cl}=15$ to 22$)$ for those with N17. There was no difference in the male groups. Disability pension rates increased linearly with age.
Among those with only basic education, $46 \%$ of women and $44 \%$ of men obtained a disability pension.

\section{Multivariate analysis}

Cox proportional hazards analysis (Table 2) showed age to be the strongest predictor of obtaining a disability pension. Subjects with an $\mathrm{H} 82$ or $\mathrm{N} 17$ diagnosis aged above 49 years had a HR of 6.6 compared to those aged less than 40 years. The elevated risk related to $\mathrm{H} 82$ diagnosis increased after adjusting for sociodemographic variables. Subjects with only basic education had an almost doubled risk compared to those in the highest educational group, controlled for age and income. After adjusting for diagnosis, age, and education, there was no income effect. There was no sex difference when all other variables were controlled for. The increased risk of disability pension among women with an $\mathrm{H} 82$ diagnosis remained in the stratified regressions.

\section{DISCUSSION}

\section{Summary of main findings}

Dizziness/vertigo is an infrequent cause of long-term sickness absence; the annual incidence for women of 7.5/10 000 at risk (vocationally active) and for men of $3.2 / 10000$ at risk (vocationally active). Among both sexes, $41 \%$ were diagnosed with vertigo. One-quarter of women and men obtained a disability pension. Low education was a strong predictor of obtaining a 
disability pension, while an $\mathrm{H} 82$ diagnosis was a risk factor for women only. The strongest predictor was age, probably caused by increasing comorbidity, a difficult labour market, and more lenient treatment of applications with increasing age. ${ }^{25,26}$

\section{Strength and limitations of the study}

This is the first population-based study on occupational consequences of dizziness. Sick-leave data are regarded as reliable and objective. The ICPC is a well-known classification instrument, ${ }^{23,24}$ and confidentiality reduced the risk of 'false' diagnoses. ${ }^{27}$ Weaknesses of register-based studies are lack of clinical data except for diagnoses, lack of information related to work conditions, and the fact that the diagnoses cannot be validated. Since cases were identified through the ICPC codes, patients whose dizziness was linked to mental health or cardiovascular problems were not included. The baseline data were recorded in 1997. The process of application, approval and delivery from Statistics Norway meant that the data were received in late 2005 . There has been no secular change since baseline. No major alteration in the rules for the sickness absence benefit scheme or disability pension has been introduced, and the ICPC is still used on the sickness certificates.

\section{Comparison with existing literature}

Vertigo and dizziness reflect a distinction between vestibular and non-vestibular symptoms. ${ }^{1,3}$ The possibility of differentiating between types of dizziness is disputed, ${ }^{3,11}$ although a high degree of sensitivity has been reported in identifying vertigo by history alone. ${ }^{28}$ The proportion of subjects with vertigo $(41 \%)$ was slightly higher than in previous studies. ${ }^{3-7}$ In the present study, as well as in previous studies, dizziness/vertigo was more common for women than for men in all age groups. ${ }^{7,9-14,29}$ However, women also have higher rates of sickness absence in general, ${ }^{19,30,31}$ often explained by occupational differences..$^{19,32,33}$ Less control of working conditions increases the burden on employees, especially on women in low-paid jobs. ${ }^{19}$ The present study confirmed findings of no sex difference in relation to the risk of transition from sickness absence to disability pension, ${ }^{22,30,34}$ implying that the threshold for taking sick leave is not lower among women than men.

Disability pension is granted when 'all relevant treatment and rehabilitation approaches have been applied'. Treatment in primary care typically consists of reassurance and medication to relieve symptoms, ${ }^{3,5,6,35}$ even though medication is not recommended beyond the acute stage. ${ }^{3,5,36}$ Referral to vestibular rehabilitation $^{37-40}$ is uncommon in primary care..$^{17,36,41}$ Lack of guidelines may lead to persistent complaints with disability pension as the endpoint. ${ }^{25}$ Vestibular rehabilitation could play an important role in preventing disability if applied at an early stage. ${ }^{42}$

\section{Implications for future research}

Further studies should focus on GPs' role in the management of patients with dizziness/vertigo. Attention should particularly be directed towards female patients.

\section{Funding body}

The Research Council of Norway (Health Economy Bergen). Norwegian Fund for Postgraduate Training in Physiotherapy

\section{Ethical approval}

Not applicable

\section{Competing interests}

The authors have stated that there are none

\section{Acknowledgements}

The data used in this study were provided by Statistics Norway, with permission from the Data Inspectorate. Statistics Norway is not responsible for the authors' analyses.

Discuss this article

Contribute and read comments about this article on the Discussion Forum: http://www.rcgp.org.uk/bjgp-discuss

\section{REFERENCES}

1. Drachman D, Hart C. An approach to the dizzy patient. Neurology 1972; 22: 323-334.

2. Sloane P, Coeytaux R, Beck R, Dallera J. Dizziness: state of the science. Ann Intern Med 2001; 134(9 pt 2): 823-831.

3. Hanley K, O'Dowd T, Considine N. A systematic review of vertigo in primary care. Br J Gen Pract 2001; 51(469): 666-671.

4. Sixt E, Landahl S. Postural disturbances in a 75 -year-old population: I. Prevalence and functional consequences. Age Ageing 1987; 16(6): 393-398.

5. Colledge N, Barr-Hamilton R, Lewis S, et al. Evaluations of investigations to diagnose the cause of dizziness in elderly people: a community-based controlled study. BMJ 1996; 313(7060): 788-792.

6. Bird J, Benyon G, Prevost A, Baguley D. An analysis of referral patterns in the primary care setting. Br J Gen Pract 1998; 48(437): 1828-1832.

7. Yardley L, Owen N, Nazareth I, Luxon L. Prevalence and presentation of dizziness in a general practice community sample of working age people. Br J Gen Pract 1998; 48(429): 1131-1135.

8. Labuguen RH. Initial evaluation of vertigo. Am Fam Physician 2006; 73(2): 244-251.

9. Sloane P. Dizziness in primary care. Results from the National Ambulatory Medical Survey. J Fam Pract 1989; 29(1): 33-38.

10. Hannaford P, Simpson J, Bisset A, et al. The prevalence of ear, nose and throat problems in the community: results from a national crosssectional postal survey in Scotland. Fam Pract 2005; 22(3): 227-233.

11. Neuhauser H, von Brevern M, Radke A, et al. Epidemiology of vestibular vertigo: a neurotologic survey of the general population. Neurology 2005; 65(6): 898-904.

12. Ihlebæk C, Eriksen H, Ursin H. Prevalence of subjective health complaints (SHC) in Norway. Scand J Public Health 2002; 30(1): 20-29.

13. Tibblin G, Bengtsson C, Furunes B, Lapidus L. Symptoms by age and sex. Scand J Prim Health Care 1990; 8(1): 9-17.

14. Nazareth I, Yardley L. A clinical approach to dizziness. J Com Med 2002, 9(3): 159-167.

15. Guilemany JM, Martinez P, Prades E, et al. Clinical and epidemiological study of vertigo at an outpatient clinic. Acta Otolaryngol 2004; 124(1): $49-52$.

16. Nazareth I, Landau S, Yardley L, Luxon L. Patterns of presentations of dizziness in primary care - a cross-sectional cluster analysis study. $J$ Psychosom Res 2006; 60(4): 395-401.

17. Nazareth I, Yardley L, Owen N, Luxon L. Outcome of symptoms of dizziness in a general practice community sample. Fam Pract 1999; 16(6): 616-618.

18. Kroenke K, Lucas C, Rosenberg ML, et al. One-year outcome for patients with a chief complaint of dizziness. J Gen Intern Med 1994; 9(12): 684-689. 
19. Marmot M, Feeney A, Shipley M, et al. Sickness absence as a measure of health status and functioning: from the UK Whitehall II study. J Epidemiol Community Health 1995; 49(2): 124-130.

20. Kivimaki M, Head J, Ferrie JE, et al. Sickness absence as a global measure of health: evidence from mortality in the Whitehall II prospective cohort study. BMJ 2003; 327(7411): 364.

21. Shiels C, Gabbay M, Ford F. Patient factors associated with duration of certified sickness absence and transition to long-term incapacity. $\mathrm{Br} J$ Gen Pract 2004; 54(499): 86-91.

22. Gjesdal S, Ringdal PR, Haug K, Maeland JG. Predictors of disability pension in long-term sickness absence: results from a population-based and prospective study in Norway 1994-1999. Eur J Public Health 2004; 14(4): 398-405.

23. Brage $\mathrm{S}$, Bentsen BG, Bjerkedal T, et al. ICPC as a standard classification in Norway. Fam Pract 1996; 13(4): 391-396.

24. Hofmans-Okkes IM, Lamberts H. The International Classification of Primary Care (ICPC): new applications in research and computerbased patient records in family practice. Fam Pract 1996; 13(3): 294-302.

25. Gjesdal S. From long-term sickness absence to disability pension. Bergen: University of Bergen, 2003.

26. Aarts L, de Jong P. Economic aspects of disability behaviour. Amsterdam, The Netherlands: Nord-Holland, 1992.

27. Hussey S, Hoddinott P, Wilson P, et al. Sickness certification system in the United Kingdom: qualitative study of views of general practitioners in Scotland. BMJ 2004; 328(7431): 88

28. Kroenke $\mathrm{K}$, Lucas CA, Rosenberg ML, et al. Causes of persistent dizziness. A prospective study of 100 patients in ambulatory care. Ann Intern Med 1992; 117(11): 898-904.

29. Guilemany J-M, Martínez P, Prades E, et al. Clinical and epidemiological study of vertigo at an outpatient clinic. Acta Otolaryngol 2004; 124(1): 49-52.

30. Gjesdal S, Bratberg E. The role of gender in long-term sickness absence and transition to permanent disability benefits. Results from a multiregister based, prospective study in Norway 1990-1995. Eur J Public Health 2002; 12(3): 180-186.

31. Alexanderson K, Leijon M, Åkerlind I, et al. Epidemiology of sickness absence in a Swedish county in 1985, 1986 and 1987. Scand J Soc Med 1994; 22(1): 27-34.

32. Blank N, Diederichsen F. Short-term and long-term sick-leave in Sweden: relationship with social circumstances, working conditions and gender. Scand J Soc Med 1995; 23(4): 265-272.

33. Karasek N, Theorell T. Healthy work: stress, productivity, and the reconstruction of working life. New York: Basic Books, 1990.

34. Brage S, Nygård J, Tellnes G. The gender gap in musculo-sceletal-related long-term sickness absence in Norway. Scand J Soc Med 1998; 26(1): 34-43.

35. Brandt T. Management of vestibular disorders. J Neurol 2000; 247(7): 491-499.

36. Yardley L, Donovan-Hall M, Smith $\mathrm{H}$, et al. Effectiveness of primary care-based rehabilitation for chronic dizziness. Ann Intern Med 2004; 141(8): 598-605.

37. Yardley L, Luxon L. Treating dizziness with vestibular rehabilitation BMJ 1994; 308(6939): 1252-1253.

38. Shepard N, Asher A. Treatment of patients with nonvestibular dizziness and disequilibrium. In: Herdman S (ed). Vestibular rehabilitation. Philadelphia: FA Davis, 2000: 534-544.

39. Luxon $\mathrm{L}$. Theorethical basis of physical exercice regimes and manoeuvres. In: Luxon L, Davies R (eds). Handbook for vestibular rehabilitation. Florence: Singular Publishing Group, 1997: 87-115.

40. Shepard N, Telian S. Practical management of the balance disorder patient. Florence: Singular Publishing Group, 1996.

41. Hansson E, Månsson N, Håkansson A. What happens with the dizzy patient in primary health care? Does education influence treatment? Adv Phys 2004; 6: 93-96.

42. Yardley L, Beech S, Zander L, et al. A randomized controlled trial of exercise therapy for dizziness and vertigo in primary care. $\mathrm{Br} \mathrm{J} \mathrm{Gen} \mathrm{Pract}$ 1998; 48(429): 1136-1140. 